\title{
Bodegas or Bagel Shops? Neighborhood Differences in Retail \& Household Services
}

\author{
Rachel Meltzer \\ Milano The New School for Management \& Urban Policy \\ The New School \\ 72 Fifth Avenue, Room 503 \\ New York, NY 10011 \\ meltzerr@newschool.edu \\ Jenny Schuetz \\ School of Policy, Planning \& Development \\ University of Southern California \\ 650 Childs Way, 224 RGL Hall \\ Los Angeles, CA 90089 \\ jschuetz@sppd.usc.edu \\ Last revised: \\ October 262010
}

\begin{abstract}
Social scientists studying the disadvantages of poor urban neighborhoods have focused on the quality of publicly provided amenities. However, the quantity and quality of local private amenities, such as grocery stores and restaurants, can also have important quality of life implications for neighborhood residents. In the current paper, we develop neighborhood-level metrics of "retail access" and analyze how retail services vary across New York City neighborhoods by income and racial composition. We then examine how retail services change over time, particularly in neighborhoods undergoing rapid economic growth. Results indicate that lower-income and minority neighborhoods have fewer retail establishments, smaller average establishments, a higher proportion of "unhealthy" restaurants, and in certain cases, less diversity across retail subsectors. In addition, the rate of retail growth between 1998 and 2007 has been particularly fast in neighborhoods that were initially lower-valued and experienced relatively high housing price appreciation compared to the city overall.
\end{abstract}

The authors gratefully acknowledge financial support and data access from the Furman Center for Real Estate and Urban Policy at New York University. Schuetz acknowledges financial support from USC's Advancing Scholarship in the Humanities and Social Sciences Initiative. We also thank Gabriela Gutierrez, Ray Calnan, and Stephaney Kipple for excellent research assistance. 


\section{Section 1) Introduction}

Social scientists studying the disadvantages of poor urban neighborhoods have tended to focus on the quality of publicly provided amenities, such as public schools and crime rates, or negative peer effects (Case and Katz 1991; Cutler, Glaeser and Vigdor 1999; Jargowsky 2003; Massey \& Denton 1993; Wilson 1987). However, the quantity and quality of local private amenities, such as grocery stores, restaurants, banking facilities and other retail services, can also have important quality of life implications for neighborhood residents. The “consumer city” literature suggests that attractive and abundant retail services affect a city’s ability to attract and retain high-skilled residents; by extension the quality of neighborhood retail may impact the neighborhood's growth prospects (Glaeser et al. 2001; Glaeser and Gottlieb 2006). A smaller empirical literature has shown that low-income and minority neighborhoods are typically less well served by certain types of retail and household services (Alwitt and Donley 1997; Bartie et al 2007; Carr and Schuetz 2001; Helling and Sawicki 2003; Sloane et al 2005; Powell 2007; Zenk 2005). In general, a smaller number of retail outlets implies a more limited choice, and an apparent lack of competition has led some researchers to argue that "the poor pay more” for many basic goods and services (Caplovitz 1967; Hayes 2000; Kaufman et al 1997). Therefore understanding the extent and reasons behind differences in the amount and composition of neighborhood commercial activity is an important area for research.

To date, there has been little large-scale empirical work looking at disparities in retail services across neighborhoods of varying economic and demographic compositions. Moreover, there has been no work looking at the change in neighborhood retail services over time and how these changes correspond with economic and demographic changes in 
the local population. Therefore, before we can explain the causes behind differences in neighborhood retail services, we should begin by measuring and describing these differences. The current paper moves the literature towards this end in two ways. First, we explore a number of approaches to measuring neighborhood "retail access" and compare various metrics over time and space. Second, while many previous studies focus on a single type of good or service, we consider access to a wide range of retail and household services. We combine publicly available data on business establishments at the ZIP code level with several New York City-specific data sources, including the location of all commercial and residential buildings, the location and corporate affiliation for several retail and food service chain establishments, residential population characteristics and sales values of residential properties. Using this combined dataset, we assess differences in retail access for approximately 208 neighborhoods, based on income and racial composition and differential growth rates in housing values.

Results confirm some findings from previous research, namely that lower-income and minority neighborhoods have a lower density of commercial establishments and employment, smaller average establishments, a higher proportion of "unhealthy" restaurants, and, in some cases, less diversity across retail sub-sectors. However, the patterns vary by retail type and demographics: the disparities are smaller for grocery stores, pharmacies and clothing than for food service or for retail as a whole. Perhaps surprisingly, predominantly Hispanic neighborhoods have more diverse retail and food services and greater access to retail corridors than predominantly white neighborhoods; the opposite is true for predominantly black neighborhoods. While most neighborhoods in New York City saw an increase in retail activity between 1998 and 2007, the rate of 
retail growth has been particularly fast in neighborhoods that were initially lower-valued and experienced relatively high housing price appreciation compared to the city overall. However, initially higher-valued and appreciating neighborhoods experienced relatively faster growth in the size of retail establishments.

This paper proceeds in the following way. The next section provides a review of the relevant literature. Section 3 describes the data and methodology; Section 4 summarizes the results from the current analysis. Section 5 concludes and offers some implications for designing economic development policies.

\section{Section 2) Literature Review}

Because the size of retail market areas will vary by product type, we begin by reviewing the types of retail that are likely to serve primarily neighborhood markets. We then outline several possible reasons why retail activity may differ by underlying neighborhood characteristics: variation in store operating or set-up costs, variation in purchasing power and preferences among local consumers (or residents), and institutional factors or public policies that influence commercial activity. Market area and product type

The urban economics literature provides several models of firm decision-making and retail location that provide a theoretical framework for why the size of retail markets will vary by product type. Hotelling's (1929) simple spatial model of firm location suggests that the density of stores depends on a variety of factors, including fixed costs of the store, buyer density and travel costs, all of which may vary by neighborhood economic conditions. One implication is that there will be different market sizes, and 
thus different densities of store networks, for establishments selling various products, which will translate into a hierarchy of retail networks. Retail store networks will be denser (that is, more locally based) for stores that have low fixed costs and sell goods that are highly standardized and frequently consumed, so that consumers will not be willing to travel long distances to purchase them (Berry 1967). ${ }^{\mathrm{i}} \quad$ Following DiPasquale and Wheaton (1996), we focus on the lowest geographical level of store networks: neighborhood stores whose customers are drawn primarily from within the immediate vicinity; these establishments will most likely reflect the composition of neighborhood residents. The goods most likely to be sold at neighborhood stores include groceries, health and beauty products, and general household items, such as cleaning and household supplies. These items are typically sold at grocery stores, supermarkets, convenience stores, pharmacies and general merchandise stores. In addition to retail, some service establishments primarily serve the immediate neighborhood, namely laundry services, coffee shops and limited service restaurants, gyms and beauty salons.

\section{Variation in store fixed or operating costs}

Set-up and operating costs for retailers include a number of factors, some of which vary by neighborhood and others that are specific to the firm and therefore somewhat idiosyncratic. ${ }^{\text {ii }}$ For instance, rents are likely to be higher in high-income (or high wage) neighborhoods, while insurance and security costs increase with neighborhood crime rates. Although wages for similar positions (sales clerk or shelf stocker) may be relatively similar across neighborhoods within the same metropolitan area, there is some anecdotal evidence that employee turnover or training needs are higher in low income neighborhoods (International Council of Shopping Centers 2004), 
increasing average labor costs in those areas. Two other fixed costs that are likely to vary across neighborhoods are local land use regimes (zoning of commercial uses) and characteristics of the local building stock. Specifically, restrictions against or incentives for retail occupancy can increase or reduce costs associated with initial set-up. Similarly, the inherent nature of the building stock will determine the feasibility and costs associated with adapting the particular retail business to the existing commercial space. For example, grocery stores often require enough space and a robust enough infrastructure to support freezers, while restaurants require venting from stoves and ovens (International Council of Shopping Centers 2004; Barragan 2010). Availability of suitable land parcels for development may be particularly important for large chains that have a preferred (often low-density) model for their stores (i.e. Big Box).

\section{$\underline{\text { Variation in consumer characteristics }}$}

For any given type of store/product, the Hotelling model implies that the density of store networks will be increasing in density of buyers. The stylized model assumes that buyers are uniformly distributed and have homogeneous preferences. In reality it is unlikely that all residents of a single neighborhood have the same demand function, either based on income/ability to pay or preferences, so estimating the density of actual rather than potential buyers within a given geographic area becomes more complicated. Waldfogel (2006) demonstrates that there is considerable heterogeneity across consumer preferences for such services as restaurants and media, and that preferences are strongly correlated with observable population characteristics, such as educational attainment and race/ethnicity. 
This conclusion mirrors the findings of a sizable body of literature in public health that explores the differences in the locational decisions of food establishments across neighborhoods. Powell (2007), Zenk (2005) and Alwitt and Donley (1997) demonstrate that various retailers (namely banks and supermarkets) opt not to locate in poorer ZIP codes even after controlling for purchasing power-leading the authors to conclude that retail locational decisions may hinge on a host of factors in addition to an area's market potential. Interestingly, Alwitt and Donley found that fast food restaurants were least likely to discriminate across neighborhoods, whereas Block et. al. (2004) and Sloane et. al. (2005) found that fast food restaurants were more likely to locate in poorer, predominately minority neighborhoods.

A few other empirical studies relate retail markets to local characteristics. Berry \& Waldfogel (2003) find that as market size increases, the range of product variety and quality widens, and the number of high-quality products grows. A recent study by Chapple and Jacobus (2009) of retail change in the San Francisco Bay Area finds that retail revitalization is most strongly associated with gains for middle-income neighborhoods. Zukin et. al. (2009) conduct case studies of two gentrifying neighborhoods in New York City and find a large increase in the number of independently owned (or local chain) establishments in those neighborhoods, compared to a small increase in large chain stores.

\section{Institutional Factors and Public Policies}

The models described thus far assume only market factors in the determination of local retail markets, but a variety of federal, state and local public interventions have been 
used to try to stimulate business development and job growth, particularly in lowerincome urban neighborhoods.

The largest federal policy aimed at business development, the Empowerment Zones and Enterprise Communities Initiative, provides federal tax incentives and other financial benefits to businesses that locate in over 100 designated neighborhoods in economically and socially depressed urban or rural communities (Hebert et al 2001). Empirical analysis of the EZ/EC program provides very mixed evidence on the program's effectiveness, but most find little or no effect on job or firm creation (Bondonio 2003; Busso and Kline 2008; Coopers \& Lybrand 1982; Dowall 1996; Glickman 1981; Neumark and Kolko 2008).

The Community Development Block Grant (CDBG) program provides federal funds that can be spent on a variety of activities designed to enhance neighborhood economic and social conditions broadly, including economic development programs. As with the EZ evaluations, evidence on the effects of CDBG on employment growth in targeted neighborhoods is somewhat mixed: higher spending per poor resident on economic development does seem to increase the number of businesses, but the effects vary by initial city and neighborhood conditions (Walker et al. 2002; Galster et al. 2004).

Many local governments in large cities, including New York City, have additional policies designed to encourage business creation or retention in targeted areas, such as tax abatements. Local governments can also change the feasibility and costs of commercial activity indirectly through zoning codes, by differentially allowing or restricting the uses and size of buildings. 


\section{Section 3) Methodology and data description}

In this paper we use data from the Census Bureau’s ZIP Business Pattern series (an extension of the County Business Patterns data), as well as two New York Cityspecific datasets on commercial properties and chain establishments, to develop a set of metrics that describe neighborhood retail access. We then use those metrics to establish some stylized facts about the relationship between retail activity, income and ethnic composition in New York City, and how retail activity changes over time in the context of neighborhood economic transition. The first part of the empirical analysis develops several different metrics, presenting summary statistics for each and examining the correlation between them, to determine whether the choice of metric is likely to affect the outcome of analysis. In the second part of the analysis, we present descriptive statistics around two research questions:

1) How do retail patterns in New York City vary by neighborhood income and racial/ethnic composition? Do these patterns differ by retail category?

2) How has retail activity in New York City changed over time? How do the changes vary by baseline neighborhood economic characteristics and economic growth?

\section{$\underline{\text { Development of retail metrics }}$}

Our primary source of data on retail and commercial activity is the ZIP Business Patterns (ZBP) dataset, collected annually by the Census Bureau. The ZBP data provide counts of the number of establishments in each industrial sector, broken out in several size categories based on the number of employees. ${ }^{\text {iii }}$ We are using the data from 1998 through 2007, which uses the North American Industrial Classification System (NAICS) 
to indicate industrial sector up to a 6-digit level of detail. ${ }^{\text {iv }}$ Because our research focuses on retail that primarily serves the residents of the immediate neighborhood, and because we are interested in quality of life implications, we have chosen to focus on four industry categories that meet these criteria: supermarkets (NAICS 6-digit code 445110), pharmacies and personal care stores (NAICS 3-digit code 446), clothing stores (NAICS 3-digit code 448), and food service establishments (NAICS 3-digit code 722). To provide some context we also look at the total number of establishments in retail (NAICS 2-digit code 44-45) and food service and hospitality (NAICS 2-digit code 72).

For each of these industrial groupings, we construct four metrics at the ZIP code level. We match each ZIP code to the land area of the ZIP Code Tabulation Area (ZCTA) from the 2000 census, which allows us to calculate the density of establishments per acre, by industry-ZIP-year (because land areas vary widely by ZCTA, comparing simple counts of establishments across ZCTAs may be misleading). ${ }^{\mathrm{v}}$ Second, we estimate the total employment by industry-ZIP-year, using the counts of establishments in each size category, and again use the land area to calculate employment density. ${ }^{\mathrm{vi}}$ Third, we combine the employment and establishment counts to calculate the average size of establishments by number of employees. Fourth, to measure the diversity of establishments, we construct a set of Herfindahl indices for each grouping. The Herfindahl index is calculated according to the equation shown below:

$$
H=\sum_{i=1}^{n} s_{i}^{2}
$$

where $s_{i}$ is the share of establishments in category i for a given industrial grouping. The index values range from zero to one, with higher numbers indicating greater concentration or less diversity. For example, if all the establishments in a ZIP code were 
in the same industry, then the share for that industry would be equal to one, as would the value of the index. For the retail Herfindahl index, we use the share of establishments in each of the 12 three-digit NAICS categories within the 2-digit retail industry (NAICS code 44-45). For the food service Herfindahl index, we use each of the four 4-digit categories within the 3-digit food service category (NAICS code 722). The subcategories within each index are shown in Table 1. All ZBP-based metrics are constructed as averages across all years in the sample (1998-2007) at the industry-ZIP level. ${ }^{\text {vii }}$

Our fifth metric of retail access draws on a different data source and focuses on geographic distance between residential and commercial properties. Using 2006 property-level data from the NYC Department of Finance Real Property Assessment Database and the NYC Department of City Planning PLUTO Database, which identify the location and use type of all properties in the city, we calculate the share of all residential building area within one-quarter and one-half mile of a commercial corridor. Using GIS mapping techniques, commercial corridors are identified as clusters of retail building area and properties classified under commercial zoning overlays (that permit retail use in mixed-use areas). A map of the retail corridors is displayed in Appendix Figure A.

The ZBP has two main advantages as a data source: because it is collected annually, it can be used to examine changes over time, and it is available for all ZIP codes across the country, allowing consistent analysis for multiple cities. A notable drawback to the ZBP, however, is that it provides no information on the type or quality of goods and services within each industrial category. For instance, one of the categories of 
interest is supermarkets. The 6-digit NAICS code for this category (445110) captures a wide range of store sizes and types, from branches of large national chains, such as Safeway and Kroger, to small, independently owned neighborhood stores or bodegas. viii Although these stores will overlap somewhat in goods offered, bodegas generally carry a much narrower range of products than traditional supermarkets, and may differ from supermarkets (and from one another) by quality and price. The same is true for our other categories of interest (notably food service).

To examine differences across neighborhoods in the quality of goods and services, we supplement the ZBP data with information on the location and corporate affiliation for a large number of regional and national chains in New York City, collected by the Center for an Urban Future (2009). From this database, we identify 98 chains that correspond to our categories of interest: all food services, some clothing and apparel (selected to cover a range of price points, adults of both genders and children, and with a large enough number of franchises to offer room for spatial variation), pharmacies, tax preparation services, gyms and some home goods. The full list of chains selected is shown in Appendix Table A. We then aggregate the data to the ZIP code level, calculating the total number of chain establishments and, within that, the number of chain restaurants. Of the restaurants, we flag certain chains as "unhealthy” fast food (shown in Appendix Table A), and calculate the share of chain restaurants that are "unhealthy" (Neal 2006; Pillsbury 2010; Warde et al 1999). For illustration, we also identify four iconic chains - McDonalds, Subway, Dunkin Donuts and Starbucks. McDonalds is the most prevalent fast food chain (it is third out of all chains, after Dunkin Donuts and Subway) with predominately unhealthy food choices. Subway also has a large number of 
locations and advertises itself as a healthier alternative that is still low-cost. Dunkin Donuts and Starbucks both offer coffee and baked goods (and we make no claims about their comparative health values), but at different price points, in quite different environments, and their marketing strategies target different clientele. To identify some quality differences within our category of greatest interest, supermarkets, we augment data from the CUF chain database with online searches to assemble a list of locations for a large number of multi-establishment grocery store firms present in New York City. The list of firm names is shown in Appendix Table B. We use this to calculate the number of chain supermarkets in each ZIP code, and identify several chains as "upscale"; these chains typically carry more organic or locally provided foods, have a large fresh produce section, and offer hard-to-obtain or expensive specialty items.

One of the purposes of this paper is to determine what types of metrics should be used to describe retail access, and whether the choice of metric is likely to affect the patterns observed. Having created five separate metrics for several industry categories, we calculate pairwise correlations between all the retail metrics, shown in Table 4 . Testing the relationship between retail activity and neighborhood characteristics

To identify patterns of retail activity across neighborhoods in New York City, we calculate summary statistics of each of the metrics described above and compare them in several ways. As described in Section 2, we expect that the amount and type of retail activity will vary by purchasing power, consumer preferences and store costs. Thus we will compare retail metrics across neighborhoods with underlying differences in variables that proxy for purchasing power and preferences, specifically household income and racial/ethnic composition. ${ }^{\text {ix }}$ We also briefly address one potential difference in store 
costs; this part of the analysis is discussed in the next section. All data on population characteristics for ZIP codes are taken from the 2000 census of population and housing. In order to account for variation in size across the ZIP codes, we weight the summary statistics by population. As shown in Table 3, ZIP code areas in New York City exhibit significant differences from one another in underlying population characteristics, such as population density, income and ethnic composition. The measures of retail activity and access also vary substantially across neighborhoods. In addition, the average population of a ZIP code in New York City is approximately 43,000, large enough to be a market area for neighborhood stores.

To understand how differences in two key characteristics, income and racial/ethnic composition, affect patterns or retail activity, we compare retail metrics by these characteristics. Specifically, we compare the average value for each of our retail metrics (density of establishments and employment, average size, Herfindahl index, residential access, and the counts of various chains) for ZIPs in which average household income is less than $80 \%$ of the average income for New York City to ZIPs with average household income above $80 \%$ of the city average income $(\$ 58,505$ in constant 2000 dollars). To assess the correlation with ethnic composition, we compare retail metrics for ZIPs that are super-majority non-Hispanic white (at or above 60\%) with ZIPs that have a super-majority of black or Hispanic residents.

\section{Changes in retail activity over time}

In addition to comparing level differences in retail metrics, we are interested in how retail presence has changed over time, and whether those changes reflect underlying changes in neighborhood characteristics. Thus we calculate the growth rate for each of 
our retail metrics from 1998 to 2007 (annual changes tend to be quite small and somewhat noisy). The growth rate is calculated using a standard measure:

$$
g_{i, 98-07}=\frac{\left(\operatorname{Re} \text { tail }_{i, 07}-\operatorname{Re} \text { tail }_{i, 98}\right)}{0.5 *\left(\operatorname{Re} \operatorname{tail}_{i, 07}+\operatorname{Re} \operatorname{tail}_{i, 98}\right)}
$$

in which Retail $_{i, 98}$ is the retail metric in industry $i$ in 1998 and Retail $l_{i, 07}$ is the retail metric in industry $i$ in 2007. As discussed in several previous papers that have used this measure, this growth rate provides a symmetric growth rate. By using an average of retail metrics in the beginning and ending years rather than just the beginning year in the denominator, we reduce potential measurement error associated with large deviations from average retail activity (see Davis et al 1996, Haltiwanger et al 2010 for more discussion). To analyze these changes in retail we stratify the sample of ZIPs in two ways: by initial economic status as of 1998 and by transition in economic status between 1998 and 2007. Since we do not have any measures of income at the ZIP Code level after 2000, we use instead residential housing sales data to identify the initial and change in economic status for each neighborhood in New York City. ${ }^{\mathrm{x}}$ We obtain NYC Department of Finance residential sales data for all New York City ZIP Codes from the Furman Center for Real Estate and Urban Policy at New York University. The data provide us with the average price per unit for all residential sales transactions in New York City between 1998 and 2007. From these data, we construct relative measures of neighborhood housing values for every neighborhood $i$ in year $t$ :

$$
\text { RelativeZIP_Avg PricePU } U_{i, t}=Z_{-} I P_{-} \text {Avg PricePU } U_{i, t} / N Y C_{-} \text {Avg PricePU }
$$


In order to differentiate neighborhoods based on their initial economic status, we calculate this ratio for all ZIP Codes in 1998 and classify neighborhoods with relative average housing values less than 0.8 as "Low Value". Neighborhoods with relative average housing values greater than or equal 0.8 are classified as "Moderate/High Value".

We then classify the neighborhoods based on their relative change in housing values between 1998 and 2007. We classify neighborhoods as "Upgrading” if they experience a percentage gain in average housing values (absolute, not relative) that is greater than the percentage change in average housing values for the city overall (housing values for New York City on average increased by 120\% between 1998 and 2007). Neighborhoods with percentage changes in average housing values less than those experienced for the city overall are classified as "Stable/Lagging”.

Since we are interested in observing how changes in retail manifest themselves in low-income neighborhoods, we first compare changes in the retail metrics across lowvalue neighborhoods that are upgrading and stable/declining. In addition, we want to compare changes in retail activity to those experienced by relatively higher income neighborhoods. Therefore, we also calculate the difference in change between low-value upgrading and stable/declining neighborhoods and compare this to the same difference across moderate-high value neighborhoods. The initial retail landscapes are quite different across low- and moderate/high- value neighborhoods (retail activity is significantly lower in low- value neighborhoods), and therefore we conduct this simplified "difference-in-difference" in order to avoid any upward bias in our estimates of retail change in low- value neighborhoods. 


\section{$\underline{\text { Additional data issues }}$}

A possible concern with the ZBP data is the consistency of the industrial classification system. According to the census, in the surveys used to construct the ZBP database, establishments are self-classified by employee or contact at the company, based on revenues. This raises the possibility that similar types of establishments may be classified differently, particularly for establishments engaged in multiple activities. For instance, as described above, bodegas could be classified as grocery stores, because they sell food items. Many but not all of these stores also prepare and sell some fresh food, such as made-to-order deli sandwiches, coffee and bagels. Depending on the share of revenues received from these activities (or the knowledge of the employee filling out the survey), a bodega may be counted in the ZBP as either grocery store (NAICS code 4451) or limited service restaurant (NAICS code 7222), while performing largely similar functions. Similar ambiguity in the NAICS codes may be present for other types of establishments as well. Classification of the same establishment may also change over time, even if the establishment does not change functions. ${ }^{\mathrm{xi}}$

\section{Section 4) Results}

In this section, we provide summary statistics of the various retail metrics to describe the amount, type and mix of retail access and activity in New York City. We describe variation in retail metrics across neighborhoods by income and ethnic composition, and changes over time, stratified by economic growth. xii How can we characterize retail activity in New York City? 
All neighborhoods in New York City have at least some amount of retail activity; there are no entirely residential neighborhoods in the city. However, there is considerable variation in the quantity of retail activity, measured by the density of establishments and shown in Figure 1. Table 3 also displays a selection of the retail metrics and demonstrates that neighborhoods across the city are diverse in terms of retail density, the size of retail establishments and the diversity of stores and services. While residents, on average, have great access to retail (nearly $90 \%$ of all residential space is within $1 / 4$ mile of a retail corridor), there are neighborhoods where this is the case for less than 10 percent of residentially-occupied space.

Because one of the purposes of this analysis is to determine what metric or combination of metrics should be used to characterize retail, it is worth asking to what degree the various metrics are correlated with one another, both within and across industry categories. If the retail metrics are not strongly correlated, that implies that the choice of metric (in our analysis, intended to serve as the dependent variable) may affect the results of the analysis. In Table 4, we show simple pairwise correlation coefficients between each metric for groceries, all retail establishments, all food service establishments, and chains. In general, the measures of establishment density across the categories are highly correlated (ranging from 0.70 to 0.90 ), which suggests that there is co-location among different types of retail. However, the other metrics, such as size, are not as consistently or strongly associated. Moreover, neither retail diversity (as measured by the Herfindahl index) nor retail access (as measured by distance to a retail corridor) is highly correlated with the other metrics. This suggests the need for a multi-dimensional approach to characterizing neighborhood retail activity. 
How does retail activity in New York City vary by income?

To develop a better understanding of the relationships between household income and retail activity, we compare all the retail metrics for neighborhoods with average household income above and below $80 \%$ of the city average income in $2000(\$ 58,505) .{ }^{\text {xiii }}$ In Table 5 we display the results for the primary retail and food service metrics, which summarize overall retail access by neighborhood type. Consistent with theory and previous case studies, relatively higher income neighborhoods have higher densities of both establishments and employment and larger establishments on average (for retail and food service). These disparities are generally larger for food services. In addition, the Herfindahl index for food services is significantly lower, on average, in higher income neighborhoods, suggesting that they have access to a more diverse pool of food services (the Herfindahl index for retail services is also lower in higher income neighborhoods, but this difference is statistically insignificant). Although both low- and moderate/highincome neighborhoods have considerable access to retail corridors, low-income neighborhoods have significantly more access. Together, these results suggest that residents in relatively low-income neighborhoods have retail activity nearby, but that it is less dense and comprised of smaller and less diverse options (both of which could have implications for the quality and cost of the goods and services).

In Section 2 we discuss how neighborhood characteristics other than income, such as access to transit and the amount of retail space in the local building stock, may affect variation in retail density. To test the importance of these factors, we calculate the average proximity between subway and rail transit and commercial properties and the average retail space per building for each ZIP. ${ }^{\text {xiv }}$ While Table 5 does not display these 
statistics, we find that relatively low-income neighborhoods have greater access to transit and more retail space per building. Therefore, in spite of possessing some characteristics that would, theoretically, make these neighborhoods more appealing to retail businesses, they still face less retail access overall.

Next we drill down to finer industry categories to better understand variations in access to specific quality-of-life retail. Again, we compare retail activity across low- and middle/high-income neighborhoods. These results are displayed in Table 6. Overall, the pattern echoes that for retail access more generally. The density (in terms of establishments and employment) is significantly higher in relatively high-income neighborhoods, and the magnitude is the largest for food services; none of the other differences compare, in terms of magnitude, with the differences found among retail establishments more broadly (which are consistently much larger). The retail establishments are also larger in higher income neighborhoods, a pattern that is particularly stark for grocery stores. The grocery stores, however, are slightly denser in lower income neighborhoods, and there is not a statistically significant difference in the density of large grocery stores across the two types of neighborhoods (this result, however, is not replicated using the employment density measure). Therefore, it appears that lower income neighborhoods are not as severely disadvantaged when it comes to "necessity" services and goods, such as groceries and drugstores; restaurants and food establishments, however, disproportionately locate in higher income neighborhoods.

Finally, we compare the prevalence of chain stores and restaurants across lowand middle/high-income neighborhoods. The results in Table 7 indicate that higher income neighborhoods have more chain stores and restaurants. In addition, chains in 
poorer neighborhoods tend to be more unhealthy (35\% compared to $21 \%$ of chain restaurants in higher income neighborhoods). Note that the difference in McDonalds locations is about two times that for Subway locations. Dunkin Donuts are more prevalent than Starbucks in both types of neighborhoods, but the Starbucks-Dunkin Donuts ratio is the highest in middle/high-income neighborhoods ( 0.54 compared to 0.03 in low-income neighborhoods and 0.41 citywide). While we cannot make a clear-cut comparison on the health aspects of Starbucks versus Dunkin Donuts, the latter certainly offers a lower-cost option and markets itself to a different clientele. The difference in the number of gyms is also stark: middle/high-income neighborhoods have, on average, one gym, while low-income neighborhoods have just 0.29 . This result, together with the statistics on chain food stores, conveys a rather unhealthy environment for residents in low-income neighborhoods. Finally, we see that lower income neighborhoods actually have significantly more chain supermarkets, but they have no "upscale” markets. While poorer neighborhoods likely do not suffer from lack of access to a Whole Foods or Zabar's, this may point to disparities in access to fresh produce or other healthy foods. How does retail activity in New York City vary by race/ethnic composition?

We replicate the same analyses across neighborhoods stratified by supermajority race/ethnicity. Table 8 displays the results for the primary retail access metrics. Consistent with the income results, neighborhoods with predominantly black and Latino residents have lower establishment and employment densities and smaller establishments than those with predominantly white residents. Predominantly white neighborhoods also have significantly more diverse food service activity than predominantly black neighborhoods (as indicated by the lower Herfindahl index); retail diversity in Latino 
neighborhoods, however, is greater than that in predominantly white neighborhoods. In addition, residents in predominantly Hispanic neighborhoods on average live closer to retail corridors (the opposite is true for predominantly black neighborhoods, compared to predominantly white neighborhoods). In sum, neighborhoods with predominantly minority populations (which also tend to be poorer) have access to fewer and smaller stores and services. Retail diversity and physical access to retail services, however, varies by race/ethnicity. Residents in predominantly Latino neighborhoods on average live closer to retail and have more diverse retail options; residents in predominantly black neighborhoods, however, have less physical access to retail services and somewhat less diverse options.

As for access to transit and prevalence of retail space, predominantly black neighborhoods generally have more rail access than and about the same amount of retail space per building as predominantly white neighborhoods. Predominantly Hispanic neighborhoods, however, have significantly less access to transit and more retail space per building. Again, it appears that any disadvantage (or advantage in the case of predominantly Hispanic neighborhoods) in retail access is not solely driven by these costrelated factors.

Table 9 shows the results for finer, quality-of-life retail categories, and indicates that overall minority neighborhoods have relatively lower densities (for establishments and employment) and smaller establishments for local basic services like groceries, drugstores, clothing and food services. One exception is groceries, which are more densely located in Latino neighborhoods relative to predominantly white neighborhoods; they do tend to be smaller, which could represent mostly bodega or deli-type outfits 
rather than general supermarkets (on average 6 employees compared to about 19 in predominantly white neighborhoods). As with the income results, these differences tend to be the largest for food service establishments.

The last set of results for chain stores and restaurants are displayed in Table 10. Predominantly black and Hispanic neighborhoods have significantly fewer chains and considerably more "unhealthy" chain restaurants (41\% and 30\% for black and Latino neighborhoods, respectively, compared to $13 \%$ for predominantly white neighborhoods). Consistent with the income results, predominantly minority neighborhoods have fewer Starbucks relative to Dunkin Donuts, fewer gyms and no "upscale” supermarkets. Predominantly Hispanic neighborhoods, however, have more chain groceries overall, although the previous set of results suggests that they are, on average, smaller. How does retail activity in New York City vary over time?

In this section we review the results from the dynamic analysis, which looks at changes in retail activity between 1998 and 2007 for low- and moderate/high-valued neighborhoods undergoing economic transitions. ${ }^{\mathrm{xv}}$ The first column of Table 11 shows the changes in four retail metrics for the city as a whole, and columns 2 and 3 show the metrics for low-valued neighborhoods that are either upgrading or stable/lagging. The fourth and fifth columns display the difference in retail change across upgrading and stable/lagging neighborhoods, for both low-valued and high-valued neighborhoods. We present the statistics for four retail categories, in order to pick up any variation among types of service. ${ }^{\text {xvi }}$

Both upgrading and stable/lagging low-valued neighborhoods are growing in terms of retail activity. This is consistent with most of New York City, and the outer- 
boroughs in particular, where most of the low-valued neighborhoods are located (see Figure 2). Moreover, upgrading neighborhoods are generally outpacing the stable/lagging neighborhoods, and about half of these differences are statistically significantly different from zero. Upgrading neighborhoods are receiving significantly more food service and clothing establishments (per acre) compared to stable/lagging neighborhoods, but the change in density and size of retail establishments more generally is indistinguishable across the two types of neighborhoods (with the exception of employee density, which is marginally statistically significant). In addition, all lowvalued neighborhoods are becoming more homogeneous in terms of retail services (the Herfindahl index is increasing), but the upgrading neighborhoods are doing so at a slower rate (there is no discernible difference in food service diversity). This reflects the general trend towards larger chains (which might actually offer a wider range of product options within each store location). That said, the more substantial changes in retail activity for economically upgrading neighborhoods are consistent with increasing buying power and, perhaps, shifts in consumer preferences, i.e. towards larger, chain stores.

As a second comparison, we calculate the same statistics for moderate/highvalued neighborhoods and derive the difference in retail change between the neighborhoods that were upgrading and stable/lagging (displayed in the last column of Table 11). We then compare this difference to the difference in retail change calculated for the low-valued neighborhoods (i.e. compare the two right-hand columns of Table 11). Overall, both low- and high/moderate-valued neighborhoods exhibit the same change patterns across upgrading and stable/declining neighborhoods. However, in terms of establishment densities, low-valued and upgrading neighborhoods are generally 
outpacing their stable/lagging comparison neighborhoods more so than high-valued and upgrading neighborhoods (except for food services, which is growing at a relatively slower pace for low-valued and upgrading neighborhoods). The results for employee densities show the reverse: high-valued and upgrading neighborhoods are generally outpacing their stable/lagging comparison neighborhoods more so than low-valued and upgrading neighborhoods (again, with the exception of food services). Similarly, except for food service establishments, higher valued and upgrading neighborhoods are outpacing comparable stable/lagging neighborhoods in establishment size more so than low-valued neighborhoods. These results suggest that while lower-valued neighborhoods are growing relatively faster in terms of retail establishment density, they are not attracting as many larger businesses (again, this might be due to differential location choices of larger chains). Lastly, while retail activity in higher valued and upgrading neighborhoods is becoming more homogeneous, it is doing so at a faster relative pace than low-valued and upgrading neighborhoods (compared to similar stable/lagging neighborhoods). The opposite is true for diversity of food services.

In sum, low-valued neighborhoods appear to fare better (in terms of retail activity) if they are economically upgrading, compared to similar, economically stable/lagging neighborhoods. However, initially higher-valued and appreciating neighborhoods experienced relatively faster growth in the size of retail establishments.

\section{Section 5) Conclusions and policy implications}

Scholars have dedicated a great deal of rigor and thought to understanding the nature of and mechanisms behind residential neighborhood change. While we expect 
commercial amenities to change along with the residential population, and anecdotal evidence generally supports this, essentially no quantitative research has focused on neighborhood commercial change. In the current paper, we aim to fill this gap by providing a much-needed assessment of local retail establishments and the neighborhoods they serve. First, we construct and compare various metrics of "retail presence", and find that a single measure is not sufficient for capturing the multidimensional nature of retail presence. While the densities of establishments and employment are strongly and positively correlated, measures of size, access and diversity are generally negatively and weakly correlated with density measures.

Second, we analyze how retail services vary across neighborhoods with different economic and demographic characteristics. Results show that low-income neighborhoods have lower densities of both establishments and employment, smaller average establishment size and less diverse retail composition. However, the size of disparities varies by retail category: poor neighborhoods are more disadvantaged in food service than in retail, and within retail, the differences are smallest for basic necessities, such as grocery stores and pharmacies. Low-income neighborhoods have fewer chain stores and restaurants, somewhat contrary to conventional wisdom. Supporting prior findings, a much higher proportion of chain restaurants in poor neighborhoods are unhealthy fast food establishments, and there are many fewer gyms available. Lowincome neighborhoods actually have a higher number of chain supermarket branches, but are less likely to have upscale supermarkets, possibly a proxy for food quality. Similar disparities exist when comparing predominantly white neighborhoods to predominantly black and Latino ones. Predominantly Latino neighborhoods, however, do have more 
diverse retail and food services and greater physical access to retail corridors than predominantly white neighborhoods.

Third, we examine changes in retail activity over time. We find that by almost all measures, retail access has improved in New York City between 1998 and 2007, and that it improved particularly rapidly in low-value neighborhoods that experienced upgrading, or gentrification. However, initially higher-valued and appreciating neighborhoods experienced relatively faster growth in bigger retail establishments over this same time period. Together, these results suggest that retail is quite sensitive to changes in neighborhood economic or demographic characteristics.

A number of areas remain for future research. This paper focuses exclusively on New York City, which differs from many other U.S. cities in its size, density, and integration of residential and commercial activities throughout many neighborhoods. Thus an important next step is to conduct similar analyses and verify whether the relationships between income, race and retail access hold true in other cities. ${ }^{\text {xvii }}$ Second, as new neighborhood-level data becomes available from the 2010 census (and the 200509 average of the ACS), it will become possible to examine more directly how retail patterns have changed in neighborhoods undergoing economic and demographic change. This may help to illuminate some of the causes behind the disparities - if low incomes are the main source of limited retail access, then retail should increase in neighborhoods experiencing rising incomes. Additional research in this area should help policymakers better construct programs to help residents in low-income and minority neighborhoods gain access to a broader range of goods and services, healthier food options and generally improve neighborhood quality of life. 
The purpose of this paper is not to evaluate the success of existing economic development policies, but based on our results, we pose several questions about how future programs might be designed. First, should eligibility be defined through constant geographic boundaries, as is the case for programs such as federal empowerment zones? As shown in Figure 3, although there is some geographic clustering of poor and minority neighborhoods, rigid geographic boundaries are somewhat of a blunt instrument if the intent is to target investment towards these neighborhoods. In addition, retail markets may span broader or more distinct areas than those defined by racial or economic clusters.

A second question is whether policies should target or favor businesses based on size. Many traditional economic development policies are intended to help small, locally owned "mom and pop" businesses. Such assistance is thought to improve opportunities for entrepreneurs and assist wealth building within the community. However, our research finds that poor and minority neighborhoods currently have much smaller average stores for nearly all the retail categories examined. This implies a smaller range of product choices within each store, and to the extent that economies of scale exist, may result in higher prices than in larger establishments. Moreover, larger stores by definition offer more opportunities for employment. Thus, although small-business friendly policies may be popular among business owners, it is not clear that they are advantageous for either consumers or potential workers in low-income neighborhoods. Alternatively, perhaps the public programs could subsidize certain types of products (for example healthier ones) for smaller businesses that cannot offer those goods at competitive prices. 
Thirdly, should economic development policies treat all types of commercial activity as equally desirable? Policies that encourage manufacturing or business incubation may provide employment opportunities but will not directly address the discrepancies in access to grocery stores, clothing or healthy food service options. Targeted policies around health-related retail may be more effective at alleviating consumption disparities than more broadly framed tax abatements. Policymakers should consider whether the primary purpose of each program is to encourage jobs or benefit consumers, and whether these goals are mutually inclusive. 


\section{References}

Alwitt, L. and T. Donley. 1997. "Retail Stores in Poor Neighborhoods.” Journal of Consumer Affairs 31: 139-164.

Barragan, Roberto. September 9 2010. Presentation at Federal Reserve Bank of Kansas City, Economic Development in Underserved Communities conference.

Bartie, P. and T. Blakely, J. Pearce, K. Witten. 2007. “Neighborhood Deprivation and Access to Fast Food Retailing: A National Study." American Journal of Preventive Medicine 32(5): 375-82.

Berry, B. 1967. Geography of Market Centers and Retail Distribution. Englewood Cliffs, NJ: Prentice Hall.

Berry, Steven T. and Joel Waldfogel. 2003. “Product Quality and Market Size.” NBER working paper \#9675.

Block, J., R. Scribner, and K. DeSalvo. 2004. "Fast food, race/ethnicity, and income: A geographic analysis.” American Journal of Preventive Medicine 27(3): 211-217.

Bondonio, Daniele. 2003. "Do Tax Incentives Affect Local Economic Growth? What mean impacts miss in the analysis of Enterprise Zone policies.” U.S. Census Bureau, Center for Economic Studies WP 03-17.

Busso, Matias and Patrick Kline. 2008. "Do Local Economic Development Programs Work? Evidence from the Federal Empowerment Zone Program”. Cowles Foundation Discussion Paper No. 1638; Yale Economics Department Working Paper No. 36.

Caplovitz, David. 1967. The Poor Pay More: Consumer Practices of Low-Income Families. Free Press.

Carr, James and Jenny Schuetz. 2001. Financial Services in Distressed Communities: Framing the Issue, Finding Solutions. Washington, DC: Fannie Mae Foundation.

Case, A. and Larry Katz. 1991. "The Company You Keep: The Effect of Family and Neighborhood on Disadvantaged Youth.” NBER Working Paper 3705.

Center for an Urban Future. 2009. "Return of the Chains."

http://www.nycfuture.org/images_pdfs/pdfs/ReturnoftheChains.pdf

Chapple, Karen and Rick Jacobus. 2009. "Retail Trade as a Route to Neighborhood Revitalization” In H. Wial, N. Pindus, \& H. Wolman (Eds.), Urban and Regional Policy and its Effects. Washington D.C.: Brookings Institution-Urban Institute. 
Coopers and Lybrand Economic Studies Group. 1982. Impact of Enterprise Zone Tax Incentives on Selected Small Businesses. Washington, D.C.: Coopers and Lybrand Economic Studies Group.

Cutler, David, Edward Glaeser and Jacob Vigdor. 1999. “The Rise and Decline of the American Ghetto.” Journal of Political Economy 107(3): 455-506.

Davis, Steven, John Haltiwanger, Scott Schuh. 1996 . Job Creation and Destruction. Cambridge, MA: MIT Press.

DiPasquale, Denise and William Wheaton. 1996. Urban Economics and Real Estate Markets. Boston: Prentice Hall.

Dowall, David. 1996. “An Evaluation of California’s Enterprise Zone Programs”. Economic Development Quarterly 10(4): 352-368.

Galster, G., C. Walker, C. Hayes, J. Johnson, and P. Boxall. 2004. "Measuring the impact of Community Development Block Grant spending on urban neighborhoods.” Housing Policy Debate 15 (4): 903-34.

Glaeser, Edward, Jed Kolko and Albert Saiz. 2001. “Consumer City.” Journal of Economic Geography 1: 27-50.

Glaeser, Edward and Joshua Gottlieb. 2006. "Urban Resurgence and the Consumer City.” Urban Studies 43(8): 1275-1299.

Glickman, N.J. 1981. "Emerging Urban Policies in a Slow-growth Economy: Conservative Initiatives and Progressive Responses in the U.S.” International Journal of Urban and Regional Research 5 (4): 492-527.

Haltiwanger, John, Ron Jarmin and C.J. Krizan. 2010. “Mom-and-Pop meet Big-Box: Complements or substitutes?” Journal of Urban Economics 67(1): 116-134.

Hayes, Lashawn R. 2000. "Do the Poor Pay More? An Empirical Investigation of Price Dispersion in Food Retailing.” Princeton Department of Economics, Industrial Relations Working Paper No. 446.

Hebert, Scott, et al. 2001. "Interim Assessment of the Empowerment Zones and Enterprise Communities (EZ/EC) Program: A Progress Report.” http://www.huduser.org/publications/econdev/ezec_rpt.html

Helling, Amy and David Sawicki. 2003. "Race and Residential Accessibility to Shopping and Services.” Housing Policy Debate 14(1-2): 69-84.

Hotelling, H. 1929. “Stability in competition.” Economic Journal 39: 41-57. 
International Council of Shopping Centers. 2004. Developing Successful Retail in Underserved Urban Markets.

Jargowsky, Paul. 2003. Poverty and Place: Ghettoes, Barrios and the American City. New York: Russell Sage.

Kaufman, Philip R., James M. MacDonald, Steve M. Lutz, and David M. Smallwood. 1997. "Do the Poor Pay More for Food? Item Selection and Price Differences Affect Low-Income Household Food Costs.” Agricultural Economics Report No. 759.

Massey, Douglas and Nancy Denton. 1993. American Apartheid. Cambridge MA: Harvard University Press.

Neal, Zachary. 2006. “Culinary Deserts, Gastronomic Oases: A Classification of US Cities.” Urban Studies 43(1): 1-21.

Neumark, David and Jed Kolko. 2008. "Do Enterprise Zones Create Jobs? Evidence from California's Enterprise Zone Program.” NBER Working Paper \# 4530.

Pillsbury, Richard. 2010. "From Hamburger Alley to Hedgerose Heights: Toward a Model of Restaurant Location Dynamics.” The Professional Geographer 39(3): 326-344.

Powell L., et. al. 2007. "Food Store Availability and Neighborhood Characteristics in the United States.” Preventive Medicine 44(3): 189-195.

Schuetz, Jenny, Jed Kolko and Rachel Meltzer. 2010. "Is the 'Shop Around the Corner' a Luxury or a Nuisance? The relationship between income and neighborhood retail patterns.” Working paper.

Sloane, D.C., L.B. Lewis, L.M. Nascimento. 2005. “Assessing Healthy Food Options in South Los Angeles Restaurants.” American Journal of Public Health 95(4): 668-673.

Waldfogel, Joel. 2008. "The median voter and the median consumer: Local private goods and population composition.” Journal of Urban Economics 63: 567-582.

Walker, Chris, Chris Hayes, George Galster, Patrick Boxall and Jennifer Johnson. 2002. “The Impact of CDBG Spending on Urban Neighborhoods.” Washington, DC: The Urban Institute.

http://www.huduser.org/Publications/PDF/CDBGSpending.pdf

Ward, Alan, Lydia Martens and Wendy Olsen. 1999. “Consumption and the Problem of Variety: Cultural Omnivorousness, Social Distinction and Dining Out.” Sociology 33(1): 105-127. 
Wilson, William J. 1987. The Truly Disadvantaged. Chicago: University of Chicago Press.

Zenk, S., et. al. 2005. "Neighborhood Racial Composition, Neighborhood Poverty, and the Spatial Accessibility of Supermarkets in Metropolitan Detroit." American Journal of Public Health 95: 660-667

Zukin, Sharon, Valerie Trujillo, Peter Frase, Danielle Jackson, Tim Recuber, and Abraham Walker. 2009. "New Retail Capital and Neighborhood Change: Boutiques and Gentrification in New York City.” City and Community 8(1): 47-64. 
Figure 1: Density of retail establishments by ZIP Code (2007)

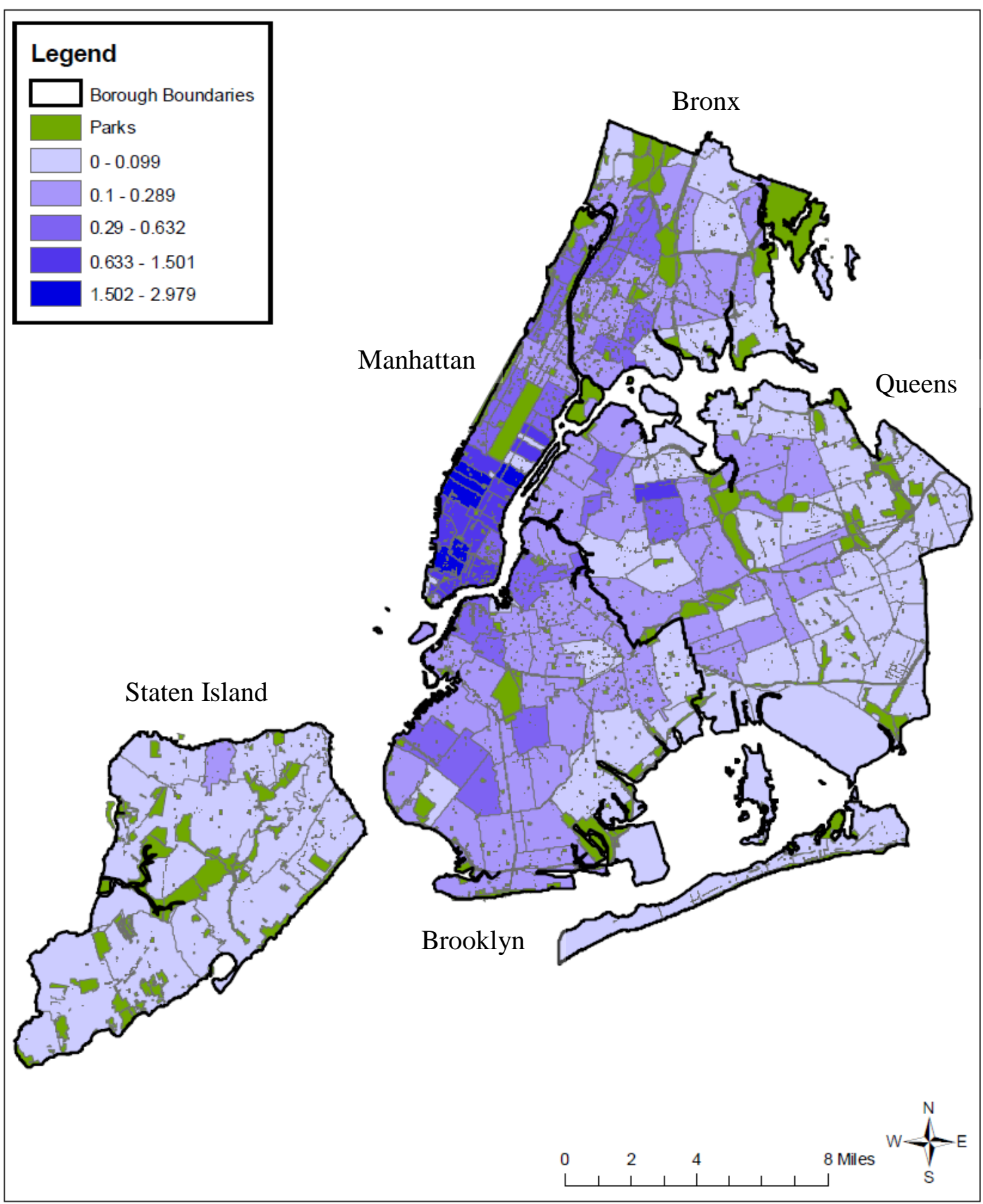


Figure 2: Percentage change in retail establishment density (1998-2007)

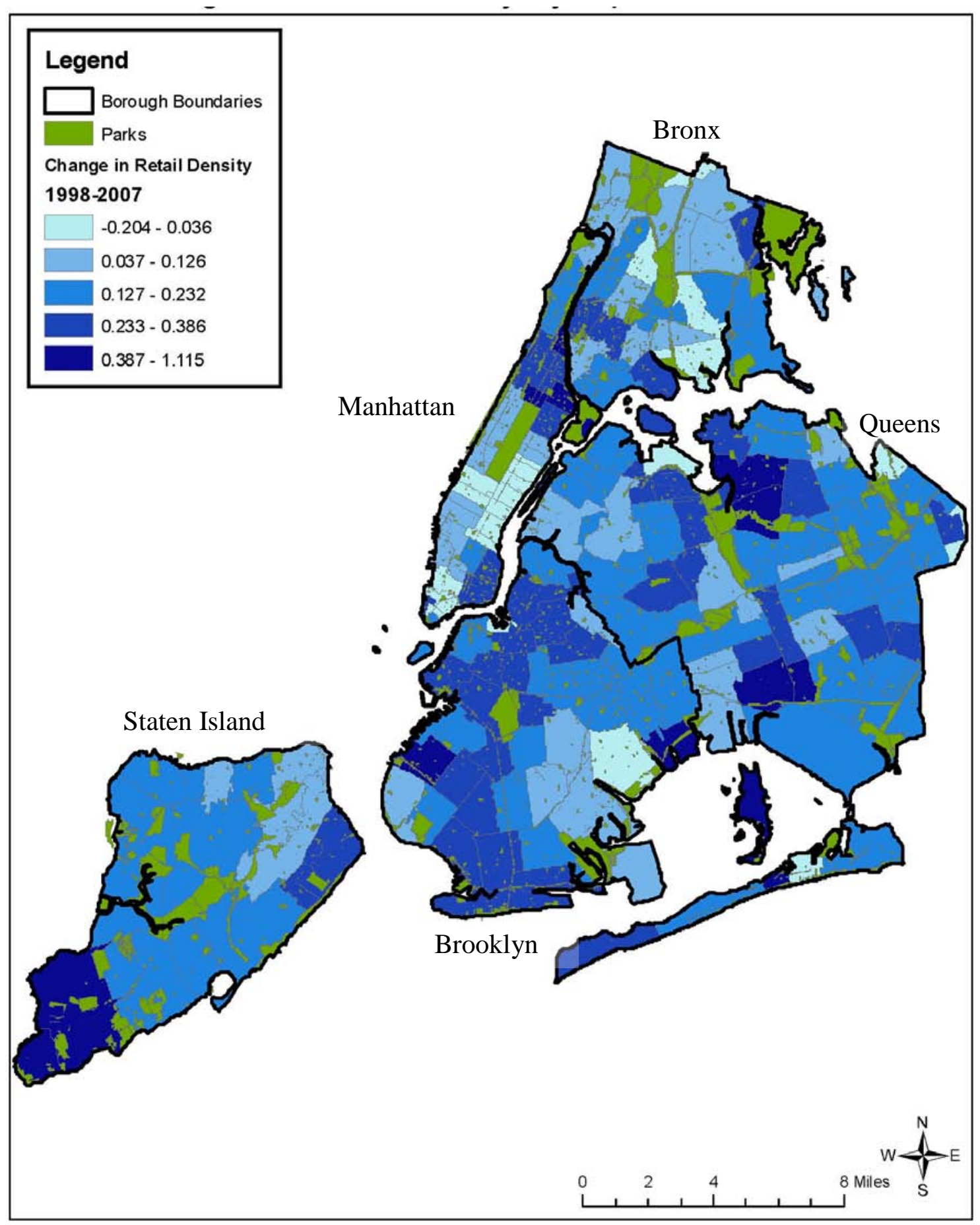


Figure 3: Density of retail establishments (2007) and Average HH Income (2000)

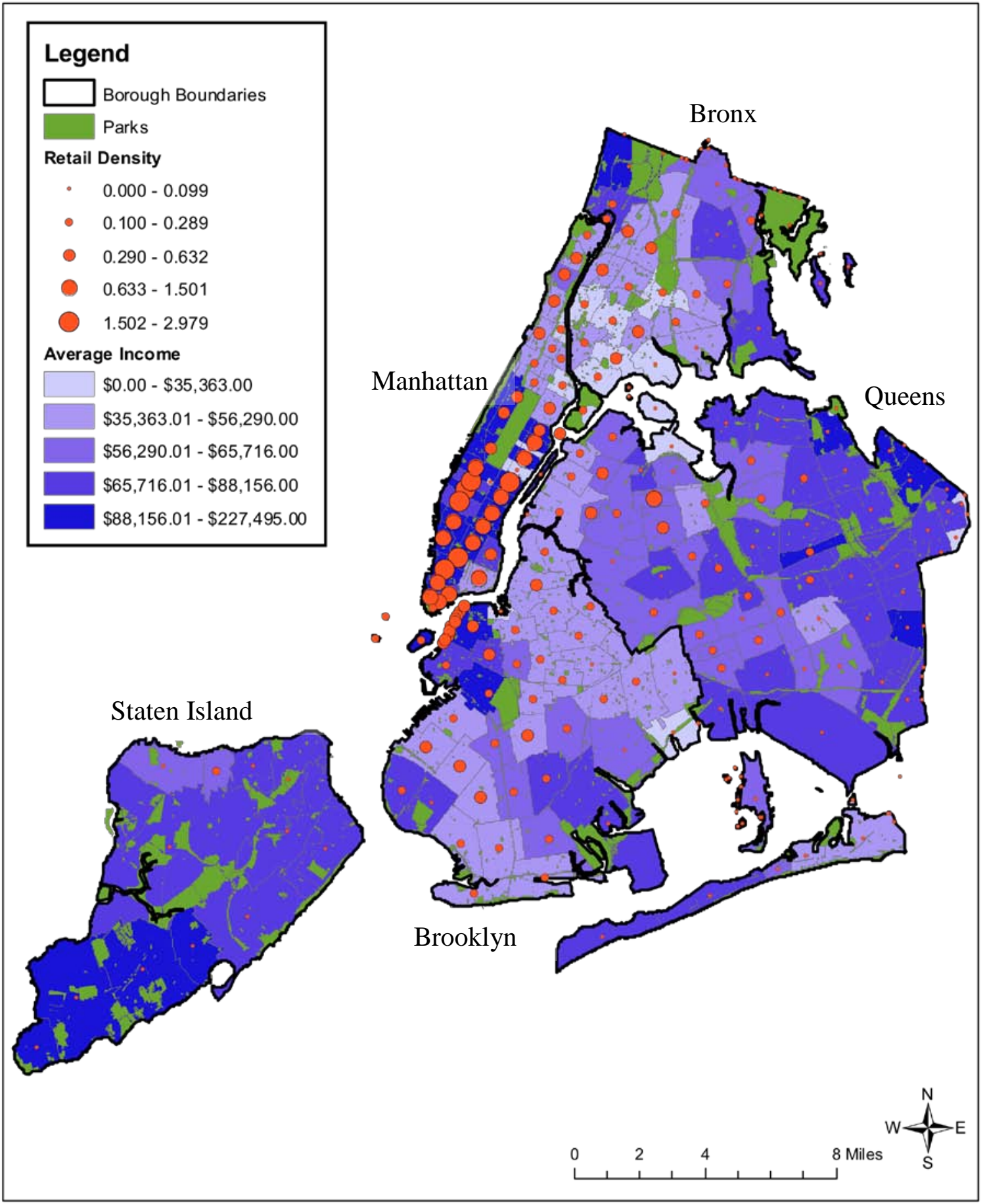


Table 1: $\quad$ Retail and food service sub-sectors

\begin{tabular}{|r|r|}
\hline NAICS code & Industry sub-sector \\
\hline 44 & Retail \\
442 & Motor Vehicle \& Parts Dealers \\
443 & Furniture \& Home Furnishings Stores \\
444 & Electronics \& Appliance Stores \\
445 & Building Material, Garden Equip \\
446 & Food \& Beverage Stores \\
447 & Health \& Personal Care Stores \\
448 & Gasoline Stations \\
451 & Sporting Goods, Hobby, Book, \& Music Stores \\
452 & General Merchandise Stores \\
453 & Miscellaneous Store Retailers \\
454 & Nonstore Retailers \\
\hline 722 & Food service \\
7222 & Full-Service Restaurants \\
7223 & Limited-Service Eating Places \\
7224 & Special Food Services \\
& Drinking Places (Alcoholic Beverages) \\
\hline
\end{tabular}

Source: NAICS 
Table 2: Variable definitions and sources

\begin{tabular}{|c|c|c|}
\hline \multirow{2}{*}{$\begin{array}{c}\text { Variable } \\
\text { Primary retail metrics }\end{array}$} & Definition & Source \\
\hline & \multirow{6}{*}{$\begin{array}{l}\text { \# of establishments in ZIP } \\
\text { divided by land area (acres) } \\
\text { \# of establishments in ZIP } \\
\text { divided by land area (acres) } \\
\text { Total employment in ZIP divided } \\
\text { by total estabs } \\
\text { Herfindahl index of diversity for } \\
\text { retail, food service } \\
\% \text { of residential sq. ft. w/in } 1 / 4 \text {, } \\
1 / 2 \text { mile of commercial corridor }\end{array}$} & \multirow{4}{*}{$\begin{array}{l}\text { ZBP (1998-2007), Census } \\
2000 \\
\text { ZBP (1998-2007), Census } \\
2000 \\
\text { ZBP (1998-2007) }\end{array}$} \\
\hline Est/land & & \\
\hline Emp/land & & \\
\hline Emp/est & & \\
\hline Herfindahl & & ZBP (1998-2007) \\
\hline $\begin{array}{l}\text { Share res } \mathrm{w} / \mathrm{in} 1 / 4 \text { mile } \\
\text { commercial }\end{array}$ & & $\begin{array}{l}\text { GIS calculations using } \\
\text { RPAD }\end{array}$ \\
\hline \multicolumn{3}{|l|}{ Chain retail metrics } \\
\hline Chain stores & $\begin{array}{l}\text { \# of retail estabs in selected } \\
\text { chains }\end{array}$ & CUF, 2009 \\
\hline Chain restaurants & $\begin{array}{l}\text { \# of restaurant estabs in selected } \\
\text { chains }\end{array}$ & CUF, 2009 \\
\hline \% unhealthy & $\begin{array}{l}\text { \# of fast food chains/total chain } \\
\text { restaurants }\end{array}$ & CUF, 2009 \\
\hline Gyms & \# of estabs in selected gym chains & CUF, 2009 \\
\hline Chain groceries & $\begin{array}{l}\text { \# of estabs in selected grocery } \\
\text { chains }\end{array}$ & Authors' search online \\
\hline$\%$ upscale & $\begin{array}{l}\text { \# of upscale groceries/\# chain } \\
\text { groceries }\end{array}$ & Authors' search online \\
\hline \multicolumn{3}{|l|}{ Population characteristics } \\
\hline Medium-upper income & $\begin{array}{l}\text { ZIP income }>=80 \% \text { of NYC } \\
\text { average household income }\end{array}$ & Census (2000) \\
\hline Low income & $\begin{array}{l}\text { ZIP income }<80 \% \text { of NYC } \\
\text { average household income }\end{array}$ & Census (2000) \\
\hline Non-Hispanic White & $\begin{array}{l}>60 \% \text { ZIP population Non- } \\
\text { Hispanic white }\end{array}$ & Census (2000) \\
\hline Black & $>60 \%$ ZIP population black & Census (2000) \\
\hline Hispanic & $\begin{array}{l}>60 \% \text { ZIP population Hispanic } \\
\text { (all races) }\end{array}$ & Census (2000) \\
\hline Low-value & $\begin{array}{l}\text { ZIP average (residential) sales } \\
\text { price }<80 \% \text { NYC average price }\end{array}$ & $\begin{array}{l}\text { DoF residential sales data } \\
\text { (1998), Furman Center }\end{array}$ \\
\hline Upgrading & $\begin{array}{l}\text { ZIP \% change in avg. hsg. val. } \\
\text { > NYC \% change in avg. hsg. } \\
\text { val. (1998-2007) }\end{array}$ & $\begin{array}{l}\text { DoF residential sales data } \\
\text { (1998-2007), Furman } \\
\text { Center }\end{array}$ \\
\hline Stable/Lagging & $\begin{array}{l}\text { ZIP \% change in avg. hsg. val. } \\
<=\text { NYC \% change in avg. hsg. } \\
\text { val. (1998-2007) }\end{array}$ & $\begin{array}{l}\text { DoF residential sales data } \\
\text { (1998-2007), Furman } \\
\text { Center }\end{array}$ \\
\hline
\end{tabular}


Table 3: $\quad$ Summary statistics of all variables

\begin{tabular}{|l|r|r|r|r|c|}
\hline \multicolumn{1}{|c|}{ Variable } & \multicolumn{1}{c|}{ Mean } & Std. Dev. & \multicolumn{1}{c|}{ Min } & \multicolumn{1}{c|}{ Max } & $\mathrm{n}$ \\
\hline Population & 42,762 & 26,956 & 16 & 106,415 & 208 \\
Pop/acre & 62.35 & 44.70 & 0.13 & 277.81 & 208 \\
Avg HH inc & $\$ 81,315$ & $\$ 41,431$ & $\$ 0$ & $\$ 227,494$ & 208 \\
BA plus & 36.6 & 26.9 & 0.0 & 100.0 & 208 \\
Poverty rate & 18.3 & 12.7 & 2.5 & 100.0 & 208 \\
Pct. White & 43.9 & 29.9 & 0.4 & 100.0 & 208 \\
Pct. Black & 21.8 & 26.6 & 0.0 & 93.9 & 208 \\
Pct. Hispanic & 22.0 & 19.2 & 0.0 & 79.9 & 208 \\
Sales price per unit, 1998 & $\$ 252,010$ & $\$ 231,578$ & $\$ 24,931$ & $\$ 2,130,190$ & 171 \\
\% change in sales prices, 1998-2007 & $138.2 \%$ & $160.5 \%$ & $-26.6 \%$ & $1354.2 \%$ & 170 \\
Est/land (Retail) & 0.26 & 0.46 & 0.00 & 2.79 & 208 \\
Emp/land (Retail) & 2.69 & 5.94 & 0.00 & 48.36 & 208 \\
Emp/est (Retail) & 9.78 & 8.28 & 2.50 & 95.25 & 208 \\
Herfindahl (Retail) & 0.24 & 0.19 & 0.10 & 1.00 & 208 \\
Share of Res within 1/4 mile & 0.85 & 0.22 & 0.02 & 1.00 & 163 \\
Share of Res within 1/2 mile & 0.93 & 0.17 & 0.10 & 1.00 & 124 \\
Chain stores (per acre) & 0.04 & 0.06 & 0.00 & 0.36 & 208 \\
Chain restaurants (per acre) & 0.02 & 0.05 & 0.00 & 0.29 & 208 \\
\% unhealthy & 0.23 & 0.16 & 0.00 & 0.75 & 208 \\
Gyms (per acre) & 0.00 & 0.00 & 0.00 & 0.04 & 208 \\
Chain groceries (per acre) & 0.00 & 0.01 & 0.00 & 0.04 & 208 \\
\% upscale & 0.03 & 0.11 & 0.00 & 0.80 & 208 \\
\hline
\end{tabular}

Note: population statistics are from 2000; business statistics are ZIP-industry averages across 10 years of ZBP data (1998-2007); chain statistics are calculated as of 2009. 
Table 4: $\quad$ Correlation of selected retail metrics

\begin{tabular}{|c|c|c|c|c|c|c|c|c|c|c|c|c|c|}
\hline & \multicolumn{3}{|c|}{ Grocery } & \multicolumn{3}{|l|}{ All retail } & \multicolumn{2}{|l|}{ Food svce } & \multirow[b]{2}{*}{ Emp/est } & \multirow[b]{2}{*}{$\begin{array}{l}\text { Herf } \\
\text { retail }\end{array}$} & \multirow[b]{2}{*}{$\begin{array}{l}\text { Chain } \\
\text { Store } \\
\text { dens } \\
\end{array}$} & \multirow[b]{2}{*}{$\begin{array}{l}\% \\
\text { unhealthy }\end{array}$} & \multirow[b]{2}{*}{$\begin{array}{l}\text { Starbucks- } \\
\text { DD }\end{array}$} \\
\hline Variable & Est/land & Emp/land & Emp/est & Est/land & Emp/land & Emp/est & Est/land & Emp/land & & & & & \\
\hline Grocery & & & & & & & & & & & & & \\
\hline Emp/land & 0.592 & & & & & & & & & & & & \\
\hline Emp/est & -0.150 & 0.461 & & & & & & & & & & & \\
\hline All retail & & & & & & & & & & & & & \\
\hline Est/land & 0.729 & 0.576 & 0.015 & & & & & & & & & & \\
\hline Emp/land & 0.615 & 0.643 & 0.133 & 0.935 & & & & & & & & & \\
\hline Emp/est & -0.079 & 0.333 & 0.540 & -0.007 & 0.082 & & & & & & & & \\
\hline Food svce & & & & & & & & & & & & & \\
\hline Est/land & 0.698 & 0.663 & 0.087 & 0.901 & 0.870 & 0.033 & & & & & & & \\
\hline Emp/land & 0.569 & 0.630 & 0.142 & 0.822 & 0.864 & 0.079 & 0.917 & & & & & & \\
\hline Emp/est & 0.191 & 0.437 & 0.284 & 0.174 & 0.250 & 0.667 & 0.214 & 0.326 & & & & & \\
\hline Herf retail & 0.259 & 0.261 & 0.100 & -0.064 & -0.023 & 0.097 & 0.000 & 0.032 & 0.232 & & & & \\
\hline Chain store dens & 0.660 & 0.582 & 0.044 & 0.824 & 0.841 & 0.028 & 0.905 & 0.854 & 0.223 & -0.058 & & & \\
\hline \% unhealthy & -0.136 & -0.275 & -0.188 & -0.203 & -0.236 & -0.188 & -0.256 & -0.247 & -0.218 & -0.347 & -0.227 & & \\
\hline Starbucks-DD & 0.484 & 0.654 & 0.263 & 0.666 & 0.702 & 0.246 & 0.747 & 0.822 & 0.483 & 0.516 & 0.717 & -0.370 & \\
\hline $\begin{array}{l}\text { w/in } 1 / 4 \text { mile of } \\
\text { retail corridor }\end{array}$ & 0.477 & 0.253 & -0.269 & 0.312 & 0.244 & -0.218 & 0.282 & 0.219 & -0.042 & 0.064 & 0.274 & -0.078 & 0.158 \\
\hline
\end{tabular}

Note: Correlation coefficients for ZBP metrics are from 2007. 
Table 5: $\quad$ Retail Access: Primary retail metrics by income

\begin{tabular}{|c|c|c|c|c|}
\hline & NYC & $\begin{array}{l}\text { Middle-upper } \\
\text { income }\end{array}$ & $\begin{array}{c}\text { Low } \\
\text { income }\end{array}$ & Difference \\
\hline \multicolumn{5}{|l|}{ Est/land } \\
\hline Retail & 0.256 & 0.269 & 0.216 & $0.053 * * *$ \\
\hline Food Service & 0.136 & 0.153 & 0.082 & $0.070 * * *$ \\
\hline \multicolumn{5}{|l|}{ Emp/land } \\
\hline Retail & 2.488 & 2.821 & 1.421 & $1.400 * * *$ \\
\hline Food Service & 2.166 & 2.641 & 0.650 & $1.991 * * *$ \\
\hline \multicolumn{5}{|l|}{ Emp/est } \\
\hline Retail & 9.208 & 9.897 & 7.032 & $2.865 * * *$ \\
\hline Food Service & 11.582 & 12.574 & 8.509 & $4.066 * * *$ \\
\hline \multicolumn{5}{|l|}{ Herfindahl } \\
\hline Retail & 0.232 & 0.231 & 0.237 & -0.006 \\
\hline Food Service & 0.448 & 0.444 & 0.460 & $-0.016 * * *$ \\
\hline \multicolumn{5}{|l|}{ Share of Res within } \\
\hline $1 / 4$ mile & 0.824 & 0.854 & 0.933 & $-0.079 * * *$ \\
\hline $1 / 2$ mile & 0.948 & 0.944 & 0.967 & $-0.024 * * *$ \\
\hline $\mathrm{n}$ & 208 & 169 & 39 & \\
\hline
\end{tabular}

Notes: "Middle-upper income" defined as greater than $80 \%$ of NYC average household income; statistics are population-weighted ZIP-industry averages across 10 years of ZBPA data (1998-2007).

$*$, **, *** indicate statistical significance at the $10 \%, 5 \%$ and $1 \%$ levels, respectively 
Table 6: Quality-of-life retail metrics by income

\begin{tabular}{|c|c|c|c|c|}
\hline & NYC & $\begin{array}{l}\text { Middle-High } \\
\text { income }\end{array}$ & $\begin{array}{c}\text { Low } \\
\text { income }\end{array}$ & Difference \\
\hline \multicolumn{5}{|l|}{ Est/land } \\
\hline Groceries & 0.040 & 0.036 & 0.051 & $-0.015 * * *$ \\
\hline Large Groceries & 0.004 & 0.004 & 0.002 & $0.002 * * *$ \\
\hline Drugstores & 0.021 & 0.022 & 0.018 & $0.004^{* * *}$ \\
\hline Clothing & 0.039 & 0.043 & 0.027 & $0.016^{* * *}$ \\
\hline Food Service & 0.136 & 0.153 & 0.082 & $0.070^{* * *}$ \\
\hline \multicolumn{5}{|l|}{ Emp/land } \\
\hline Groceries & 0.441 & 0.475 & 0.343 & $0.132 * * *$ \\
\hline Large Groceries & 0.291 & 0.339 & 0.153 & $0.186^{* * *}$ \\
\hline Drugstores & 0.272 & 0.313 & 0.153 & $0.161^{* * *}$ \\
\hline Clothing & 0.531 & 0.629 & 0.238 & $0.390^{* * *}$ \\
\hline Food Service & 2.166 & 2.641 & 0.650 & $1.991^{* * *}$ \\
\hline \multicolumn{5}{|l|}{ Emp/est } \\
\hline Groceries & 12.76 & 14.59 & 7.53 & $7.07 * * *$ \\
\hline Drugstores & 76.61 & 80.69 & 63.91 & $16.78^{* * *}$ \\
\hline Clothing & 12.99 & 14.57 & 8.47 & $6.10^{* * *}$ \\
\hline Food Service & 10.77 & 11.50 & 8.60 & $2.90 * * *$ \\
\hline $\mathrm{n}$ & 208 & 169 & 39 & \\
\hline
\end{tabular}

Notes: "Middle-upper income" defined as greater than $80 \%$ of NYC average household income. Statistics are population-weighted ZIP-industry averages across 10 years of ZBPA data (1998-2007).*, **, *** indicate statistical significance at the $10 \%, 5 \%$ and $1 \%$ levels, respectively, based on t-test for difference in means. 
Table 7: $\quad$ Chain stores \& restaurants by income

\begin{tabular}{|c|c|c|c|c|}
\hline & NYC & $\begin{array}{l}\text { Middle-high } \\
\text { income }\end{array}$ & $\begin{array}{l}\text { Low } \\
\text { income }\end{array}$ & Difference \\
\hline Chain Stores (\#) & 22.87 & 24.11 & 18.90 & $5.21 * * *$ \\
\hline Chain Restaurants (\#) & 15.27 & 16.01 & 12.90 & $3.11 * * *$ \\
\hline "Unhealthy" (\%) & 24.7 & 21.1 & 35.2 & $-14.2 * * *$ \\
\hline Notable chains (\% of total) & & & & \\
\hline McDonalds & 6.8 & 5.8 & 9.7 & $-0.04 * * *$ \\
\hline Subway & 8.4 & 8.0 & 9.8 & $-0.02 * * *$ \\
\hline Starbucks & 3.8 & 5.0 & 0.4 & $0.05 * * *$ \\
\hline Dunkin Donuts & 11.8 & 12.2 & 10.7 & $0.01 * * *$ \\
\hline Starbucks-DD Ratio & 0.41 & 0.54 & 0.03 & $0.50 * * *$ \\
\hline Gyms (\#) & 0.86 & 1.04 & 0.29 & $0.75 * * *$ \\
\hline Chain Groceries (\#) & 3.34 & 2.92 & 4.67 & $-1.75 * * *$ \\
\hline "Upscale" (\%) & 3.2 & 4.4 & 0.0 & $4.4^{* * *}$ \\
\hline$n$ & 208 & 169 & 39 & \\
\hline
\end{tabular}

Notes: "Middle-upper income" defined as greater than $80 \%$ of NYC average household income. Statistics are population-weighted ZIP-industry averages across 10 years of ZBPA data (1998-2007). *, **, *** indicate statistical significance at the $10 \%, 5 \%$ and $1 \%$ levels, respectively, based on t-test for difference in means. 
Table 8: Retail Access: Primary retail metrics by predominant racial/ethnic group

\begin{tabular}{|c|c|c|c|c|c|}
\hline & $\begin{array}{c}\text { White } \\
\text { Non- } \\
\text { Hispanic }\end{array}$ & Black & Hispanic & $\begin{array}{c}\text { Difference, } \\
\text { White-black }\end{array}$ & $\begin{array}{c}\text { Difference, } \\
\text { White-Hispanic }\end{array}$ \\
\hline \multicolumn{6}{|l|}{ Est/land } \\
\hline Retail & 0.336 & 0.129 & 0.263 & $0.207 * * *$ & $0.073 * * *$ \\
\hline Food Service & 0.210 & 0.037 & 0.076 & $0.173 * * *$ & $0.134 * * *$ \\
\hline \multicolumn{6}{|l|}{ Emp/land } \\
\hline Retail & 4.084 & 0.874 & 1.653 & $3.209 * * *$ & $2.431 * * *$ \\
\hline Food Service & 4.479 & 0.366 & 0.676 & $4.113 * * *$ & $3.804 * * *$ \\
\hline \multicolumn{6}{|l|}{ Emp/est } \\
\hline Retail & 10.570 & 7.195 & 6.478 & $3.375^{* * *}$ & $4.092 * * *$ \\
\hline Food Service & 14.963 & 11.423 & 9.111 & $3.540 * * *$ & $5.852^{* * *}$ \\
\hline \multicolumn{6}{|l|}{ Herfindahl } \\
\hline Retail & 0.265 & 0.245 & 0.219 & 0.020 & $0.046 * * *$ \\
\hline Food Service & 0.470 & 0.519 & 0.430 & $-0.049 * * *$ & $0.040 * * *$ \\
\hline \multicolumn{6}{|l|}{ Share of Res within } \\
\hline $1 / 4$ mile & 0.873 & 0.851 & 0.960 & $0.023 * * *$ & $-0.086 * * *$ \\
\hline $1 / 2$ mile & 0.947 & 0.942 & 1.000 & $0.005 * * *$ & $-0.053 * * *$ \\
\hline $\mathrm{n}$ & 78 & 26 & 16 & & \\
\hline
\end{tabular}

Notes: Predominant racial/ethnic group defined as greater than $60 \%$ of population.

Statistics are population-weighted ZIP-industry averages across 10 years of ZBPA data (1998-2007). *,**,*** indicate statistical significance at the $10 \%, 5 \%$ and $1 \%$ levels, respectively, based on t-test for difference in means. 
Table 9: Quality-of-life retail metrics by predominant racial/ethnic group

\begin{tabular}{|r|c|c|c|r|r|}
\hline & $\begin{array}{c}\text { White } \\
\text { Non- } \\
\text { Hispanic }\end{array}$ & Black & Hispanic & $\begin{array}{c}\text { Difference, } \\
\text { White-black }\end{array}$ & $\begin{array}{c}\text { Difference, } \\
\text { White-Hispanic }\end{array}$ \\
\hline Est/land & & & & & \\
Groceries & 0.040 & 0.029 & 0.064 & $0.012^{* * *}$ & $-0.023^{* * *}$ \\
Large Groceries & 0.007 & 0.002 & 0.003 & $0.005^{* * *}$ & $0.004^{* * *}$ \\
Drugstores & 0.030 & 0.012 & 0.022 & $0.018^{* * *}$ & $0.007^{* * *}$ \\
Clothing & 0.064 & 0.017 & 0.036 & $0.047^{* * *}$ & $0.029^{* * *}$ \\
Food Service & 0.210 & 0.037 & 0.076 & $0.173^{* * *}$ & $0.134^{* * *}$ \\
\hline Emp/land & & & & & \\
Groceries & 0.724 & 0.220 & 0.377 & $0.504^{* * *}$ & $0.347^{* * *}$ \\
Large Groceries & 0.569 & 0.107 & 0.162 & $0.462^{* * *}$ & $0.407^{* * *}$ \\
Drugstores & 0.469 & 0.118 & 0.199 & $0.351^{* * *}$ & $0.270^{* * *}$ \\
Clothing & 1.067 & 0.134 & 0.298 & $0.933^{* * *}$ & $0.770^{* * *}$ \\
Food Service & 4.479 & 0.366 & 0.676 & $4.113^{* * *}$ & $3.804^{* * *}$ \\
\hline Emp/est & & & & & \\
Groceries & 19.19 & 8.86 & 6.25 & $10.330^{* * *}$ & $12.94^{* * *}$ \\
Drugstores & 91.58 & 72.99 & 61.20 & $18.586^{* * *}$ & $30.38^{* * *}$ \\
Clothing & 15.88 & 11.66 & 8.86 & $4.215^{* * *}$ & $7.01^{* * *}$ \\
Food Service & 13.24 & 8.37 & 7.82 & $4.864^{* * *}$ & $5.42^{* * *}$ \\
\hline $\mathrm{n} \quad$ & 78 & 26 & 16 & & \\
\hline
\end{tabular}

Notes: Predominant racial/ethnic group defined as greater than $60 \%$ of population. Statistics are population-weighted ZIP-industry averages across 10 years of ZBPA data (1998-2007).*, **, *** indicate statistical significance at the $10 \%, 5 \%$ and $1 \%$ levels, respectively, based on t-test for difference in means. 
Table 10: $\quad$ Chain stores $\&$ restaurants by race/ethnicity

\begin{tabular}{|c|c|c|c|r|r|}
\hline & $\begin{array}{c}\text { White } \\
\text { Non- } \\
\text { Hispanic }\end{array}$ & Black & Hispanic & $\begin{array}{c}\text { Difference, } \\
\text { White-black }\end{array}$ & $\begin{array}{c}\text { Difference, } \\
\text { White-Hispanic }\end{array}$ \\
\hline Chain Stores (\#) & 23.98 & 19.67 & 19.27 & $4.31^{* * *}$ & $4.72^{* * *}$ \\
\hline Chain Restaurants (\#) & 15.71 & 13.11 & 12.44 & $2.60^{* * *}$ & $3.27^{* * *}$ \\
"Unhealthy" (\%) & 12.8 & 40.6 & 29.6 & $-27.8^{* * *}$ & $-16.8^{* * *}$ \\
\hline Notable chains (\%) & & & & & \\
McDonalds & 4.2 & 7.7 & 9.4 & $-3.4^{* * *}$ & $-5.1^{* * *}$ \\
Subway & 7.8 & 7.1 & 11.3 & 0.7 & $-3.6^{* * *}$ \\
Starbucks & 8.9 & 0.4 & 0.7 & $8.5^{* * *}$ & $8.2^{* * *}$ \\
Dunkin Donuts & 11.5 & 10.1 & 12.1 & $1.4^{* * *}$ & -0.6 \\
\hline Starbucks-DD Ratio & 0.94 & 0.03 & 0.06 & $0.92^{* * *}$ & $0.88^{* * *}$ \\
\hline Gyms (\#) & 1.41 & 0.52 & 0.44 & $0.90^{* * *}$ & $0.98^{* * *}$ \\
\hline Chain Groceries (\#) & 2.26 & 4.25 & 3.90 & $-1.99^{* * *}$ & $-1.64^{* * *}$ \\
"Upscale" (\%) & 8.8 & 0.0 & 0.0 & $8.8^{* * *}$ & $8.8^{* * *}$ \\
\hline $\mathrm{n}$ & 78 & 26 & 16 & & \\
\hline
\end{tabular}

Notes: Predominant racial/ethnic group defined as greater than $60 \%$ of population. Statistics are population-weighted ZIP-industry averages across 10 years of ZBPA data (1998-2007).*, **, *** indicate statistical significance at the $10 \%, 5 \%$ and $1 \%$ levels, respectively, based on t-test for difference in means. 
Table 11: Does retail access improve in low-value neighborhoods that upgrade?

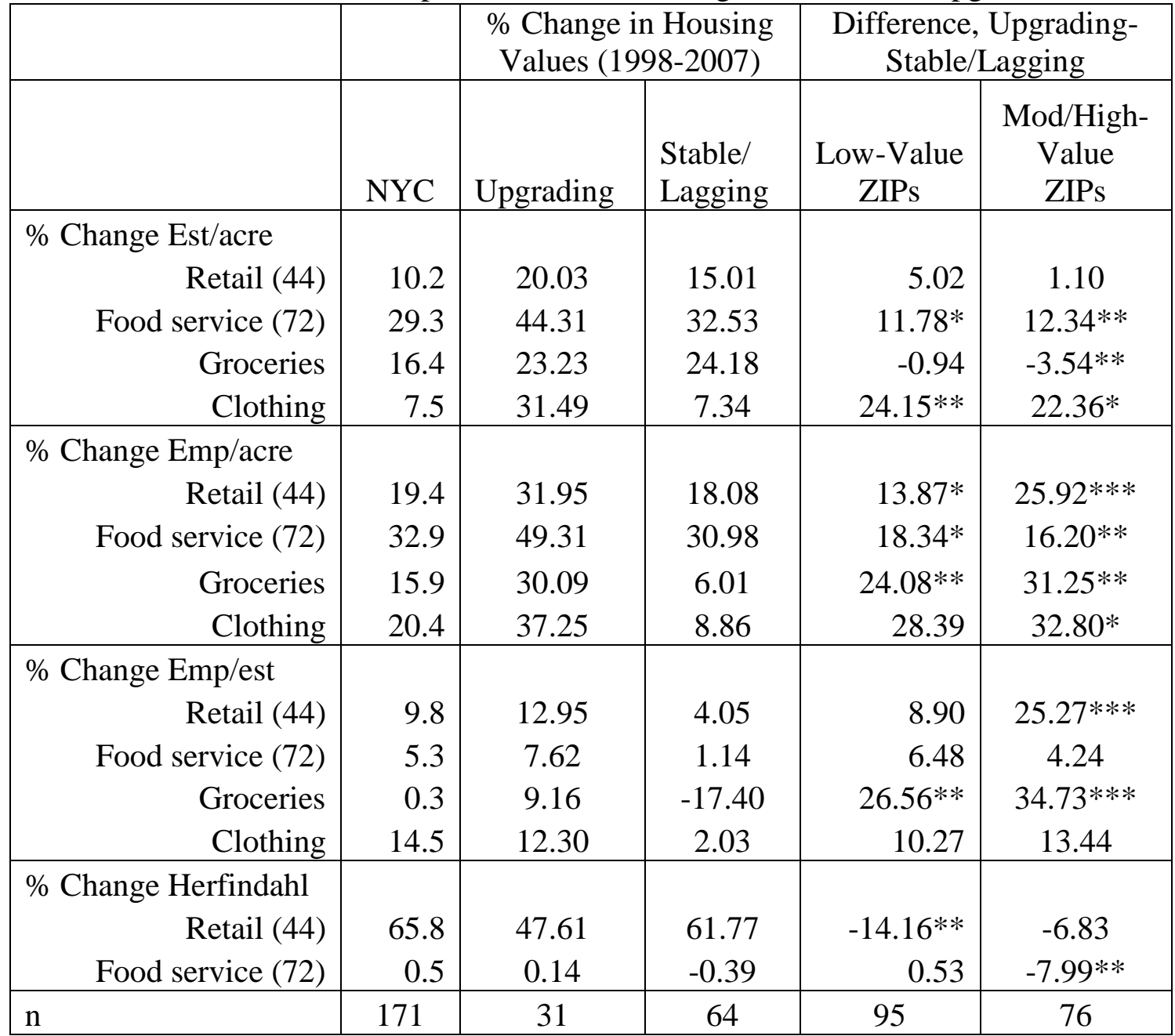

Notes: ZIPs in columns 1 and 2 had initial housing values (1998) < 80\% NYC avg. "Upgrading" defined as ZIP \% change in average housing value > NYC \% change in average housing value (1998-2007). Stable/Lagging defined as ZIP \% change in average housing value $\leq$ NYC $\%$ change in average housing value (1998-2007).

*, **, *** indicate statistical significance at the $10 \%, 5 \%$ and $1 \%$ levels, respectively, based on t-test for difference in means. 


\section{Appendix}

Figure A: Retail Corridors, New York City

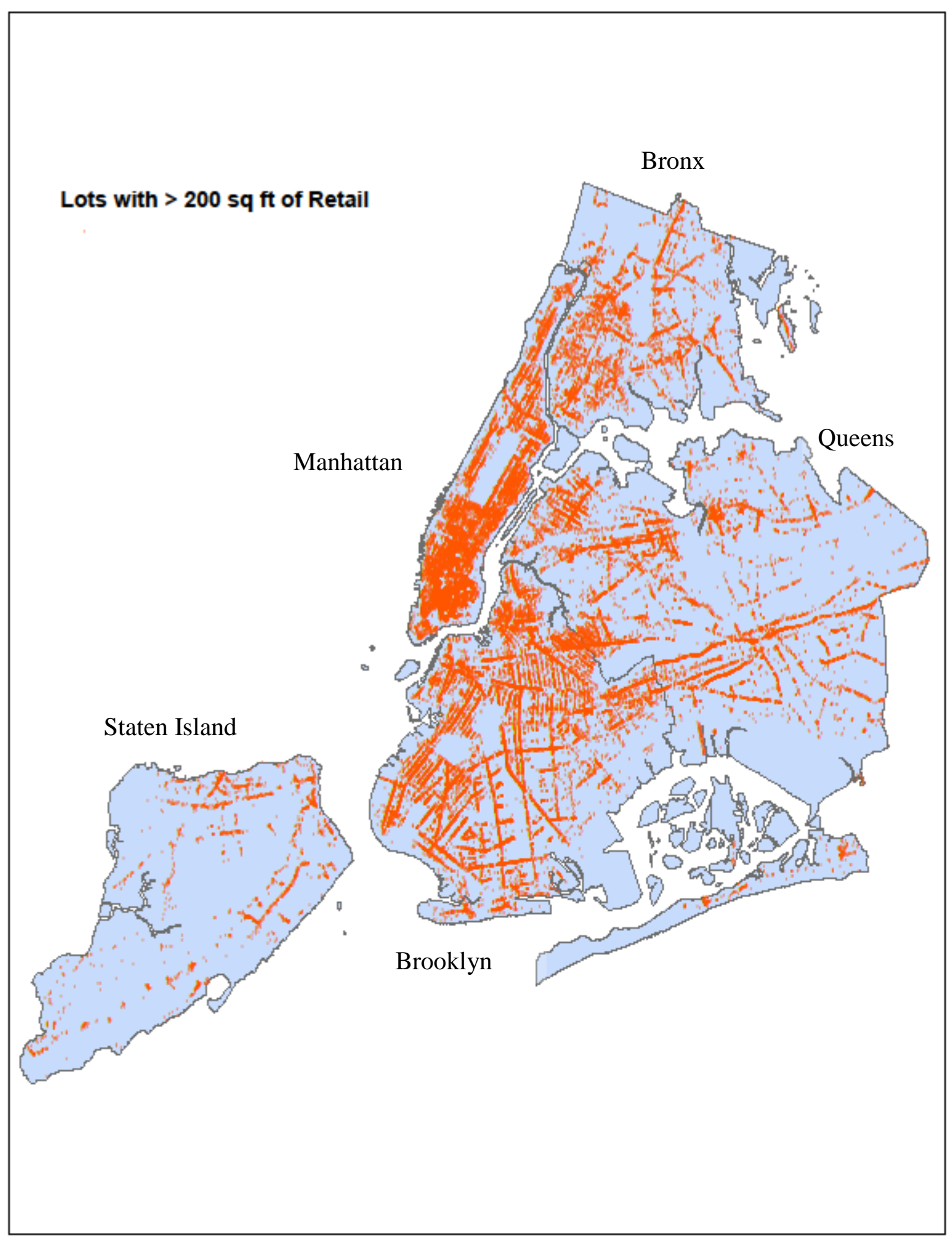


Table A: $\quad$ Chain stores and restaurants in database

\begin{tabular}{|c|c|}
\hline Category & Chain name \\
\hline Clothes \& shoes & $\begin{array}{l}\text { AMERICAN APPAREL, ANN TAYLOR, BANANA } \\
\text { REPUBLIC, BROOKLYN INDUSTRIES, FOOT LOCKER, } \\
\text { GAP, H\&M, MARSHALLS, OLD NAVY, PAYLESS, THE } \\
\text { CHILDRENS PLACE, URBAN OUTFITTERS }\end{array}$ \\
\hline Drugstore & CVS, DUANE READE, RITE AID, WALGREENS \\
\hline Financial services & H\&R BLOCK, JACKSON HEWITT, LIBERTY TAX \\
\hline Food/beverage: Fast food & $\begin{array}{l}\text { AUNTIE ANNIES*, BURGER KING*, CROWN FRIED } \\
\text { CHICKEN*, DOMINOS*, FIVE GUYS*, GOLDEN KRUST*, } \\
\text { KFC,* MASTER WOK*, MCDONALDS*, NATHANS*, PAPA } \\
\text { JOHNS*, PIZZA HUT*, POPEYES*, PRETZEL TIME*, } \\
\text { RANCH1, SBARRO*, TACO BELL*, WENDYS*, WHITE } \\
\text { CASTLE* }\end{array}$ \\
\hline Food/beverage: Other & $\begin{array}{l}\text { 7-ELEVEN, APPLEBEE'S, ARTHUR TREACHER, AU BON } \\
\text { PAIN, BASKIN ROBBINS, BEN AND JERRYS, BLIMPIE, } \\
\text { BOSTON MARKET, CARVEL, CHEVY'S, CHIPOTLE, } \\
\text { CHUCK E. CHEESE, COLD STONE CREAMERY, COSI, } \\
\text { CRUMBS, DALLAS BBQ, DUNKIN DONUTS, FAMIGLIA, } \\
\text { FRIDAYS, GLORIA JEANS COFFEE, GODIVA, HAAGEN- } \\
\text { DAZS, HALE AND HEARTY, HARD ROCK CAFÉ, IHOP, } \\
\text { JAMBA JUICE, JOHNNY ROCKETS, JUAN VALDEZ, LE } \\
\text { PAIN QUOTIDIEN, MRS FIELDS, OLIVE GARDEN, } \\
\text { OUTBACK, PANERA BREAD, PAX WHOLESOME, } \\
\text { PINKBERRY, PRET A MANGER, QUIZNOS, RED LOBSTER, } \\
\text { STARBUCKS, SUBWAY, TASTI D-LITE, TIM HORTON, } \\
\text { TWO BOOTS, UNO'S }\end{array}$ \\
\hline Gyms & $\begin{array}{l}\text { BALLY'S TOTAL FITNESS, CRUNCH, CURVES, DAVID } \\
\text { BARTON, EQUINOX, GOLD'S GYM, LUCILLE ROBERTS, } \\
\text { NY SPORTS CLUB }\end{array}$ \\
\hline Home goods & HOME DEPOT, RENT-A-CENTER \\
\hline
\end{tabular}

* Denotes "unhealthy" fast food restaurant.

Source: Center for an Urban Future 2009. 
Table B: $\quad$ Supermarket chains in database

\begin{tabular}{l}
\hline Supermarket name \\
\hline Associated Supermarkets \\
Bravo \\
Citarella* \\
Costco \\
C-Town \\
D'Agostino* \\
Fairway \\
Fine Fare \\
Food Emporium \\
Garden of Eden* \\
Gourmet Garage* \\
Gristedes \\
Key Food \\
Morton Williams \\
Pathmark \\
Trader Joe's \\
West Side Market \\
Western Beef \\
Western Beef/Junior's \\
Whole Foods* \\
* Denotes “upscale” supermarket.
\end{tabular}

Source: Center for Urban Futures 2009, additional online research by authors. 
Table C: Does retail access improve in high-value neighborhoods that upgrade?

\begin{tabular}{|c|c|c|c|}
\hline & \multicolumn{2}{|c|}{$\begin{array}{c}\text { \% Change in Housing Values } \\
(1998-2007)\end{array}$} & \multirow[b]{2}{*}{ Difference } \\
\hline & Upgrading & Stable/Lagging & \\
\hline \multicolumn{4}{|l|}{ \% Change Est/acre } \\
\hline Retail (44) & 2.96 & 1.86 & 1.10 \\
\hline Food service (72) & 29.70 & 17.35 & $12.34 * *$ \\
\hline Groceries & 4.57 & 8.11 & $-3.54 * *$ \\
\hline Clothing & 14.98 & -7.38 & $22.36 *$ \\
\hline \multicolumn{4}{|l|}{ \% Change Emp/acre } \\
\hline Retail (44) & 35.07 & 9.15 & $25.92 * * *$ \\
\hline Food service (72) & 40.06 & 23.86 & $16.20 * *$ \\
\hline Groceries & 41.94 & 10.69 & $31.25 * *$ \\
\hline Clothing & 47.75 & 14.95 & $32.80 *$ \\
\hline \multicolumn{4}{|l|}{ \% Change Emp/est } \\
\hline Retail (44) & 32.66 & 7.39 & $25.27 * * *$ \\
\hline Food service (72) & 11.16 & 6.92 & 4.24 \\
\hline Groceries & 37.84 & 3.11 & $34.73 * * *$ \\
\hline Clothing & 35.62 & 22.18 & 13.44 \\
\hline \multicolumn{4}{|l|}{ \% Change Herfindahl } \\
\hline Retail (44) & 71.65 & 78.48 & -6.83 \\
\hline Food service (72) & -4.68 & 3.32 & $-7.99 * *$ \\
\hline $\mathrm{n}$ & 18 & 58 & \\
\hline
\end{tabular}

Notes: All ZIPs had initial housing values (1998) >= 80\% NYC avg. "Upgrading” defined as ZIP \% change in avg. hsg. val. > NYC \% change in avg. hsg. val. (1998-2007). Stable/Lagging defined as ZIP \% change in avg. hsg. val. $\leq$ NYC \% change in avg. hsg. val. (1998-2007).

\footnotetext{
${ }^{\mathrm{i}}$ In the classic example, the market area for ice cream vendors will be very small, due to the highly perishable nature of the good, so in equilibrium there will be a large number of vendors each with a small market area. On the other end of the spectrum, consumers should be willing to travel long distances to purchase goods that are expensive, infrequently purchased or highly differentiated by quality, such as cars, furniture, or high-end restaurants; these retail categories will have a smaller number of establishments, each serving quite large geographic markets.

ii Many retail firm costs are not "fixed" in the traditional sense, but are also not exactly marginal. For instance, building rents are often fixed over lease terms, which may be 5 or ten years long but may offer some flexibility between leases, depending on negotiations between tenant and landlord. Likewise contracts with suppliers, insurance, utilities, etc., may be fixed over a short period of time (1-2 years), and so cannot be directly reduced with marginal productivity.

iii An establishment is defined as a "single physical location at which business is conducted or services or industrial operations are performed”. A firm may have multiple establishments, each of which are counted separately.
} 
${ }^{\text {iv }}$ Prior to 1997 the ZBP use the Standard Industrial Classification (SIC) system, which differs in several ways from the NAICS. In general, the NAICS offers a more fine-grained level of detail that is helpful for our analysis, but makes it infeasible to match counts by industry category precisely between the two coding systems.

${ }^{v}$ We were unable to match 96 ZIP codes to 2000 ZCTAs. These non-matched ZIP codes are comprised of single-buildings and P.O. boxes, constituting at most 200 retail establishments in total (less than $1 \%$ of all retail establishments in NYC). Therefore, we do not miss a great deal of retail activity in these nonmatched ZIP codes. In addition, most of these ZIP codes are located in Midtown Manhattan, and all of our analyses are robust to analyses without Midtown neighborhoods.

${ }^{v i}$ The size measure is a weighted average, using the midpoint of each size category multiplied by the number of establishments in the category. For the largest category, 1000 or more employees, we use 1000 as the average number. Very few establishments in New York City fall into this category, so any noise introduced by this approximation is likely to be small.

${ }^{v i i}$ We average across the 10 years, because individual ZIP-industry-year statistics can be noisy and actually change slowly on a year-to-year basis.

viii In this paper, we use the term "bodegas" to refer to small stores that carry a limited selection of groceries, such as canned and frozen goods, pre-packaged basic dry goods, milk, sodas and beer, and household or personal items, such as cleaning supplies and toiletries. Some also offer limited selections of fresh produce, fresh baked goods, coffee, and deli sandwiches made to order.

${ }^{\mathrm{ix}}$ We run similar analyses based on educational attainment and get substantially similar results to the income analysis. Results are available upon request from authors.

${ }^{\mathrm{x}}$ The 2010 decennial Census has not yet been released and the American Community Survey will not report income at the ZIP Code level until releasing five-year averages in late 2010.

${ }^{x i}$ Our related research using a longitudinal establishment database, the NETS dataset, confirms that establishments do change their NAICS classification over time, although overall numbers of these changes are fairly small.

${ }^{x i i}$ All of the results described in this section are robust to analyses that (i) exclude predominantly officeand retail-occupied midtown Manhattan ZIP codes and (ii) exclude all Manhattan ZIP codes, and (iii) exclude ZIP codes with low populations (less than 200) and low retail activity (less than 50 establishments).

xiii All of the results comparing low- and moderate/high-income neighborhoods, as defined above, are robust to analyses comparing retail metrics across neighborhoods with (i) income below and above the citywide median income and (ii) share of college-educated residents above and below the share of collegeeducated residents for the entire city.

${ }^{x i v}$ Both variables are constructed using NYC Department of City Planning PLUTO Database for 2006. Proximity to rail and subway transit is created using GIS maps of rail and subway entrances and calculating the average distance between thee entrances and retail properties for each ZIP code. The amount of retail space per building is calculated by dividing the aggregate amount of retail space for the ZIP code by the total number of commercial and mixed-use buildings in the ZIP code.

${ }^{x v}$ All of the results for the dynamic analysis are robust to analyses that (i) exclude predominantly officeand retail-occupied midtown Manhattan ZIP codes, (ii) exclude ZIP codes with low populations (less than 200) and low retail activity (less than 50 establishments), and (iii) other thresholds for low- and moderate/high-valued neighborhoods (specifically $60 \%, 10 \%$ and $120 \%$ of the average price per unit for New York City overall),

${ }^{x v i}$ We cannot use the chains or supermarket data in the dynamic analysis, because we have that data for only one point in time (2009).

xvii Schuetz et. al. (2010) conduct a large-scale analysis of retail and neighborhood income for 58 large U.S. metro areas. They find that retail density varies with income for certain retail types, such as food service and chain supermarkets and drugstores. In addition, average establishment size increases with income for all retail types. Retail density increases with population density, as expected, and decreases with distance to CBD and with share of owner-occupied housing. 